\title{
Developments in Diagnostic and Interventional Procedures in Lung Cancer
}

\author{
Jack A Kastelik* \\ Department of Respiratory Medicine, University of Hull and Hull York Medical School, UK
}

Submission: July 03, 2019; Published: August 12, 2019

*Corresponding author: Jack A Kastelik, Department of Respiratory Medicine, University of Hull and Hull York Medical School, East Yorkshire, UK

Keywords: Lung cancer; Endobronchial ultrasound; Pleural effusion

\section{Short Communication}

Worldwide around 1.8 million cases of lung cancer are diagnosed each year [1]. The overall 5year survival is poor at around $4 \%$ mainly due to the fact that only approximately $15 \%$ of the cases are diagnosed with the early stages of lung cancer [1]. The investigational procedures form an important part of staging and diagnosing lung cancer with timely investigations resulting in better outcomes [2]. For example, the LungBOOST trial showed that rapid diagnostic pathway shortened time from the referral to diagnosis by 15 days, which resulted in an increase by 191 days of the median survival [3]. The initial imaging tests such as a Computed Tomography (CT) of the thorax and a Positron Emission Tomography (PET) scan allow to determine staging and to guide diagnostic tests. The most important aspect of these tests is to determine the nodal staging and the presence of distant metastases. The PET scan has been shown to have sensitivity of $77.4 \%$ and specificity of $90.1 \%$ for detecting mediastinal lymph nodes involvement [4]. Nevertheless, usually further evaluation and biopsy of the mediastinal lymph nodes is of importance in managing patients with lung cancer, which nowadays is undertaken using Endobronchial Ultrasound (EBUS) or Endoscopic Ultrasound (EUS) [5]. EBUS similarly to the flexible fiberoptic bronchoscopy are composed of glass fibers, which transmit the light and the images and a working channel allowing for the suctioning, and introduction of the biopsy instruments but have 350 rather than direct visualization angle. An EBUS has an ultrasound probe, which allows real time visualization and biopsy of the lymph nodes using a 21 or 22-gauge needle with recommendation that each lymph node should be sampled 1 to 3 times and on each occasion 10 to 15 needle passes should be undertaken [6]. The current guidelines suggest that 40 to 50 procedures are required to be undertaken before proficiency in EBUS can be achieved with simulation-based training similarly to learning bronchoscopy showing to speed up learning [7-9]. Combining EBUS, which can access and sample the ATS stations 2, 3, 4, 7, 10, 11 with the EUS which examines stations $2 \mathrm{~L}, 4 \mathrm{~L}, 7,8,9$ allows for more comprehensive assessment of the mediastinal lymph nodes with reported sensitivity of $85 \%$ for detection of cancer which was similar to that of mediastinoscopy $[10,11]$. Mediastinoscopy, however is still perceived as the gold standard and in cases where mediastinal lymph node sampling with EBUS and EUS was negative for cancer, mediastinoscopy was reported to increase the sensitivity by $9 \%$ [11]. Therefore, in patients with suspicion for mediastinal lymph nodes involvement and who are candidates for radical treatment in the context of negative EBUS and EUS sampling mediastinoscopy should be considered as it may provide additional sensitivity and diagnostic yield.

Bronchoscopy remains an important procedure when assessing patients with lung cancer with over 500,000 procedures being undertaken yearly in the USA [8-12]. Bronchoscopy provides a very good tool for histological confirmation of endobronchial lung cancer. Many units now combine EBUS, EUS and bronchoscopy within one setting as this allows for the best flexibility and diagnostic strategies. In addition to the white light bronchoscopy, technology allows for an auto-fluorescence bronchoscopy that uses differential fluorescence emission, which distinguishes between the normal and abnormal mucosa, which may be of relevance in detecting very early neoplastic lesions. In the context of diagnosing peripheral lung cancer, which is not visible endo-bronchially when using fiberoptic bronchoscopy there are other diagnostic options such as a CT guided biopsy and some newer bronchoscopic techniques. One 
of them is the radial EBUS, which is a flexible bronchoscope that has an ultrasound probe allowing for a $360 \mathrm{o}$ ultrasound visualisation of peripheral solid lung lesions and biopsy [13]. The diagnostic yield from the radial EBUS was reported at $78 \%$ for the lesions greater than $20 \mathrm{~mm}$ and that of $56 \%$ for the lesions less than $2 \mathrm{~cm}[14,15]$. Another newer technique that allows to sample peripheral lesions is the navigational bronchoscopy [16]. The virtual bronchoscopy is a type of navigational bronchoscopy where the CT images are reconstructed to form a detailed bronchial tree in order to use simulation bronchoscopy as a guide and when combined with the radial EBUS this technique was shown to provide a $94.4 \%$ diagnostic yield [16-18]. Another technique namely electromagnetic navigational bronchoscopy uses a flexible bronchoscope and a guide wire with a sensor, with the electromagnetic field being used to track it into the lung lesion applying processed CT images and subsequently allowing for the sampling of the lesion [16-18]. A recent large prospective study reported diagnostic yield of the electromagnetic navigational bronchoscopy at 73\% [19]. In addition, as a result of technological developments there are some newer techniques that have been introduced such as the hybrid EBUS or the thin convex probe EBUS, which have improved angle of view and the scope flexibility with resulting benefits of endo-bronchial manoeuvrability and potentially higher diagnostic yields [9].

A proportion of patients with lung cancer develop pleural effusion, which would require formal assessment and if causing symptoms therapeutic interventions. Thoracic ultrasound has become an important technique for imaging and guiding of the pleural procedures as it has shown to improve their outcomes and to reduce their complications such as pneumothorax by around 19\% [20-22]. When diagnostic pleural biopsy is requited a local anaesthetic thoracoscopy forms an important procedural option with relatively low levels of complications $[23,24]$. The procedure involves an introduction of most commonly a rigid thoracoscope, although semi-rigid scopes are also available, into the pleural cavity and examination and sampling of the pleura $[25,26]$. The diagnostic sensitivity of the rigid thoracoscopy was reported at $94.1 \%$ with slightly lower figures for the semirigid thoracoscopy [27]. In addition, thoracoscopy allows for the pleural fluid drainage and talc pleurodesis. A newer technique auto-fluorescence thoracoscopy has been shown to have $100 \%$ sensitivity for detecting abnormal pleural lesions [28]. In some patients thoracoscopy may not be appropriate and alternative options such as CT guided biopsy of the pleura have been shown to have overall sensitivity of $87.5 \%$ [25-27].

Many patients may require diagnostic or therapeutic procedures such as ultrasound guided thoracocentesis, chest drain or indwelling pleural catheter insertion [29,30]. The decision on which procedures to undertake will depend on the patients' symptoms, prognosis and preference with studies suggesting cost benefits and symptom improvement in 95\% of cases for indwelling pleural catheter and perhaps better effectiveness of thoracoscopy when managing malignant pleural effusion [30,31]. An insertion of indwelling pleural catheter was shown to have better pleural effusion control of $82 \%$ at 30 days compared to that of $52 \%$ for chest drain and pleurodesis but no difference in controlling breathless [32-34]. However, patients who had indwelling pleural catheter compared to those who had chest drain insertion and pleurodesis were reported to have a shorter hospital stay and needed fewer number of subsequent pleural procedures [35]. In addition, in a proportion of patients with indwelling pleural catheter a spontaneous pleurodesis may occur. Moreover, there is increasing evidence that talc pleurodesis through the indwelling pleural catheter may result in a higher pleurodesis rates of $43 \%$ compared to that of $23 \%$ observed in patients who had indwelling pleural catheter drainage of the fluid alone [35]. Similarly, there are reports to suggest that the insertion of an indwelling pleural catheter at the end of the thoracoscopy procedure is safe and may reduce the hospital length of stay [36].

There is a range of possible interventional bronchoscopic techniques including Nd-YAG laser, plasma argon coagulator, cryotherapy, brachytherapy or photodynamic therapy, which could be applied mainly to manage neoplastic bronchial obstruction [37]. Similarly, bronchoscopy can be used for the insertion of stents, which main function is to maintain bronchial patency. These therapeutic techniques are of relevance in the context of the symptomatic bronchial lumen obstructing or occluding lung cancer. A recent report revealed that therapeutic bronchoscopy improved health related quality of life by around $5.8 \%$ per day of life representing most likely the aggregate of multimodality treatments [38]. An earlier study reported that laser resection of central obstructing lesion improved survival by showing $40 \%$ mortality at 7 months and $72 \%$ at 1 year compared to historical data of $76 \%$ mortality at 4 months and $100 \%$ at 7 months [39]. Another study reported better survival following Nd-Yag laser and radiotherapy of 267 days compared to historical survival of 150 days for the radiotherapy alone [40]. From the diagnostic aspects, it is therefore important to be aware that for the patients presenting with dyspnoea as a result of central airway obstruction interventional bronchoscopy if perform earlier has better effects on the health-related quality of life and improvement in breathlessness.

In conclusion, over the recent years there have been technological improvements resulting in new diagnostic and interventional procedures. These novel techniques together with the already well-established modalities are becoming important part of diagnostic and therapeutic options for patients with lung cancer. Therefore, patients with lung cancer should have access to these bronchoscopic and pleural techniques. Moreover, physicians should be aware of their indications and applications.

\section{References}

1. NICE Guidelines Updates Team (UK) (2019) Lung cancer: diagnosis and management. London: National Institute for Health and Care Excellence, UK. 
2. Neal RD, Tharmanathan P, France B, Din NU, Cotton S, et al. (2015) Is increased time to diagnosis and treatment in symptomatic cancer associated with poorer outcomes? Systematic review 112: 92-107.

3. Navani N, Nankivell M, Lawrence DR, Lock S, Makker H, et al. (2015) Lung cancer diagnosis and staging with endobronchial ultrasoundguided transbronchial needle aspiration compared with conventional approaches: An open-label, pragmatic, randomised controlled trial Lancet Respir Med 3(4): 282-289.

4. Schmidt-Hansen M, Baldwin DR, Hasler E, Zamora J, Abraira V (2014) Pet-CT for assessing mediastinal lymph node involvement in patients with suspected resectable non-small cell lung cancer. Cochrane Database Syst Rev, CD009519.

5. Groth SS, Andrade RS (2008) Endobronchial ultrasound-guided transbronchial needle aspiration for mediastinal lymph node staging in non-small cell lung cancer. Semin Thorac Cardiovasc Surg 20: 274278.

6. Gompelmann D, Eberhardt R, Herth FJ (2012) Endobronchial ultrasound. Endoscopic Ultrasound 1(2): 69-74.

7. Bolliger CT, Mathur PN, Beamis JF, Becker HD, Cavaliere S, et al. (2002) ERS/ATS statement on interventional pulmonology. Eur Respir J 19(2): 356-373.

8. Ernst A, Silvestri GA, Johnstone D (2003) Interventional pulmonary procedures: Guidelines from the american college of chest physicians. Chest 123(5): 1693-1717.

9. Stather DR, MacEachern P, Chee A, Dumoulin E, Tremblay A (2012) Evaluation of clinical endobronchial ultrasound skills following clinical versus simulation training. Respirology 17(2): 291-299.

10. Dong X, Qiu X, Liu Q Jia J (2013) Endobronchial ultrasound-guided transbronchial needle aspiration in the mediastinal staging of nonsmall cell lung cancer: A meta-analysis. Ann Thorac Surg 96(4): 15021507.

11. Annema JT, Van Meerbeeck JP, Rintoul RC, Dooms C, Deschepper E, et al. (2010) Mediastinoscopy vs endosonography for mediastinal nodal staging of lung cancer: A randomized trial. JAMA 304(2): 2245-2252.

12. Silvestri GA, Feller-Kopman D, Chen A, Wahidi M, Yasufuku K, et al. (2012) Latest advances in advanced diagnostic and therapeutic pulmonary procedures. Chest 142(6): 1636-1644.

13. Belanger AR, Akulian JA (2017) An update on the role of advanced diagnostic bronchoscopy in the evaluation and staging of lung cancer Ther Adv Respir Dis 11(5): 211-221.

14. Steinfort DP, Khor YH, Manser RL, Irving LB (2011) Radial probe endobronchial ultrasound for the diagnosis of peripheral lung cancer: Systematic review and meta-analysis. Eur Respir J 37(4): 902-910.

15. Steinfort DP, Vincent J, Heinze S, Antippa P, Irving LB (2011) Comparative effectiveness of radial probe endobronchial ultrasound versus ct-guided needle biopsy for evaluation of peripheral pulmonary lesions: A randomized pragmatic trial. Respir Med 105(11): 17041711.

16. Khan KA, Nardelli P, Jaeger A, O'Shea C, Cantillon-Murphy P, et al (2016) Navigational bronchoscopy for early lung cancer: A road to therapy. Ad Ther 33(4): 580-596.

17. Asano F, Shinagawa N, Ishida T, Tsuzuku A, Tachihara M, et al. (2015) Virtual bronchoscopic navigation improves the diagnostic yield of radial-endobronchial ultrasound for peripheral pulmonary lesions with involved bronchi on ct. Intern Med 54(9): 1021-1025.

18. Asano F, Eberhardt R, Herth FJ (2014) Virtual bronchoscopic navigation for peripheral pulmonary lesions. Respiration 88(5): 430-440.

19. Khandhar SJ, Bowling MR, Flandes J, Gildea TR, Hood KL, et al. (2017) Electromagnetic navigation bronchoscopy to access lung lesions in
1,000 subjects: First results of the prospective, multicenter navigate study. BMC Pulm Med 17(1):59-68.

20. Reddy CB, De Camp MM, Diekemper RL, Gould MK, Henry T, et al (2019) Summary for clinicians: Clinical practice guideline for management of malignant pleural effusions. Annal Am Thoac Soc 16(1): 17-21.

21. Gordon CE, Feller KD, Balk EM, Smetana GW (2010) Pneumothorax following thoracentesis: A systematic review and meta-analysis. Arch Int Med 170(4): 332-339.

22. Mercaldi CJ, Lanes SF (2013) Ultrasound guidance decreases complications and improves the cost of care among patients undergoing thoracentesis and paracentesis. Chest 143(2): 532-538.

23. Viskum K (1989) Contraindications and complications to thoracoscopy. Pneumologie 43(2): 55-57.

24. Viskum K, Enk B (1981) Complications of thoracoscopy. Poumon Coeur 37(1): 25-28

25. Mohan A, Chandra S, Agarwal D, Naik S, Munavvar M (2010) Utility of semirigid thoracoscopy in the diagnosis of pleural effusions: A systematic review. J Bronchology Interven Pulmonology 17(3): 195201.

26. Tassi GF, Marchetti GP, Aliprandi PL (2011) Advanced medical thoracoscopy. Monaldi Arch Chest Dis 75: 99-101.

27. Metintas M, Ak G, Dundar E, Yildirim H, Ozkan R, et al. (2010) Medical thoracoscopy vs ct scan-guided abrams pleural needle biopsy for diagnosis of patients with pleural effusions: A randomized, controlled trial. Chest 137(6): 1362-1368.

28. Wang F, Wang Z, Tong Z, Xu L, Wang X, et al. (2015) A pilot study of autofluorescence in the diagnosis of pleural disease. Chest 147(5): 1395-1400.

29. Clive AO, Jones HE, Bhatnagar R, Preston NJ, Maskell N (2016) Interventions for the management of malignant pleural effusions: $A$ network meta-analysis. Cochrane Database of System Rev CD010529.

30. Puri V, Pyrdeck TL, Crabtree TD, Kreisel D, Krupnick AS, et al. (2012) Treatment of malignant pleural effusion: A cost-effectiveness analysis. The Ann Thorac Surg 94(2): 374-379.

31. Van Meter ME, McKee KY, Kohlwes RJ (2011) Efficacy and safety of tunneled pleural catheters in adults with malignant pleural effusions: A systematic review. J Gen Inter Med 26(1): 70-76.

32. Demmy TL, Gu L, Burkhalter JE, Toloza EM, D’Amico TA, et al. (2012) Optimal management of malignant pleural effusions. J Natl Comp Canc Netw 10(8): 975-982.

33. Boshuizen RC, Vd NV, Burgers JA, Herder GJM, Hashemi SMS, et al. (2017) A randomized controlled trial comparing indwelling pleural catheters with talc pleurodesis. Lung Cancer 108: 9-14.

34. Muruganandan S, Azzopardi M, Fitzgerald DB, Shrestha R, Kwan BCH et al. (2018) Aggressive versus symptom-guided drainage of malignant pleural effusion via indwelling pleural catheters (ample-2): An openlabel randomised trial. Lancet Respir Med 6(9): 671-680.

35. Davies HE, Mishra EK, Kahan BC, Wrightson JM, Stanton AE, et al. (2012) Effect of an indwelling pleural catheter vs chest tube and talc pleurodesis for relieving dyspnea in patients with malignant pleural effusion: The Time 2 randomized controlled trial. JAMA 307(22): 2383-2389.

36. Kyskan R, Li P, Mulpuru S, Souza C, Amjadi K (2017) Safety and performance characteristics of outpatient medical thoracoscopy and indwelling pleural catheter insertion for evaluation and diagnosis of pleural disease at a tertiary center in canada. Can Respir J 2017: 9345324

37. Bolliger CT, Sutedja TG, Strausz J, Freitag L (2006) Therapeutic bronchoscopy with immediate effect: Laser, electrocautery, argon plasma coagulation and stents. Eur Resir J 27(6): 1258-1271. 
38. Ong P, Grosu HB, Debiane L, Casal RF, Eapen GA, et al. (2019) Longterm quality-adjusted survival following therapeutic bronchoscopy for malignant central airway obstruction. Thorax 74(2): 141-156.

39. Brutinel WM, Cortese DA, McDougall JC, Gillio RG, Bergstralh EJ (1987) A two-year experience with the neodymium-yag laser in endobronchial obstruction. Chest 91(2): 159-165.
40. Desai SJ, Mehta AC, Vander BMS, Golish JA, Ahmad M (1988) Survival experience following $\mathrm{Nd}$ : Yag laser photoresection for primary bronchogenic carcinoma. Chest 94(5): 939-944.
This work is licensed under Creative Commons Attribution 4.0 License

DOI: 10.19080IJOPRS.2019.04.555630
Your next submission with Juniper Publishers will reach you the below assets

- Quality Editorial service

- Swift Peer Review

- Reprints availability

- E-prints Service

- Manuscript Podcast for convenient understanding

- Global attainment for your research

- Manuscript accessibility in different formats ( Pdf, E-pub, Full Text, Audio)

- Unceasing customer service

Track the below URL for one-step submission https://juniperpublishers.com/online-submission.php 